\title{
Findings from a Large-Scale Empirical Research on Substance Abuse Prevention in Greece
}

\author{
Ioannis Dritsas and Maria Theodoratou* \\ Department of Social Work, School of Health and Welfare Professions, Technological Educational Institute of Patras, Greece
}

Submission: July 18, 2017; Published: July 31, 2017

*Corresponding author: Maria Theodoratou, Department of Social Work, School of Health and Welfare Professions, Technological Educational Institute of Patras, Greece, Email: mttheoria3@gmail.com

\begin{abstract}
Research indicates that combined psychosocial interventions aiming at reducing or postponing substance use and abuse in schools can be effective. Confronted with a rising number of both young and adult drug users successive geek governments have established an extensive network of prevention centers all over the country end especially in Attica where most citizens live. Our own empirical study -the first of its kind in Greece and with such a large number of both providers and receivers who participated in the research project- has taken a detailed look at both the inner workings of those centers and the actual effects of the psychosocial interventions that aim to reduce substance problems in youth as perceived by both implementers and receivers at school level. Our findings suggest that the majority of the students who participated in the psychosocial interventions expressed the views that they have been taught new coping mechanisms and have enjoyed the whole experience. Proposals are made for the role of policy makers and those involved in planning, implementing and evaluating prevention programs along with the need for more systematic research into methodological issues in the performance stages of substance prevention programs in Greece.
\end{abstract}

\section{Introduction}

Preventing substance abuse is a very important and alarming issue for global health, as the burden imposed by drug addiction is huge. Drug abuse is considered to be a very important public health problem all over the world. Moreover, it is cause of concern for health services, policy makers, prevention workers, criminal justice system, youth workers, teachers, parents. An increased awareness of comorbidity between mental and substance use disorders connects prevention with psychiatry and related disciplines. Emphasis on program evaluation has helped identify cost effective programs and policies. The integration of prevention within healthy life style policies and programs, including interventions at the school, family and community levels, is more likely to produce the desired outcomes [1].

Developing effective drug abuse prevention models is important for the following additional reasons: These intervention programs could reduce morbidity and mortality related to alcohol, tobacco, and marijuana use. Furthermore, preventing early use of these gateway substances might reduce, or prevent the use of other drugs during the developmental progression. School-based drug prevention (SBDP) programs are especially popular, with evidence suggesting their benefits to be twice that of costs [2]. It is worth notifying that among other concerns, disease is attributable to substance use disorders referring disability-adjusted life years (DALYs), years of life lost to premature mortality (YLLs), and years lived with disability (YLDs) [3].

Emphasis on program evaluation has helped identify cost effective programs and policies1. In a cost-benefit model [4] it was estimated that even small effect sizes in universal prevention interventions, in terms of delaying initiation into substance use for a few years, could lead to important savings to society over an individual's lifetime.

Similarly, the United Kingdom National Institute for Health and Clinical Excellence has suggested [5], that "a national alcohol misuse prevention program in schools would be a cost effective use of public money, if it cost $£ 75$ million and achieved at least a $1.4 \%$ absolute reduction in alcohol consumption amongst young people", a very small effect size.

Both economic models suggested that prevention programs would be a cost effective use of public money [6].

\section{Epidemiology Of Substance Abuse In Greece}

In contemporary Greek society, it is common among young people to engage in some level of experimentation with substances. Substance use occurs almost exclusively in a 
social context during early adolescence and typically involves substances that are readily available. These include marijuana, alcohol, and tobacco. Some youngsters become regular users and/or progress to marijuana, hallucinogens, and other illicit drugs whereas. The majority discontinue use after a brief period of experimentation, or fail to progress to the use of other substances.

While EKTEPN (National Center FOR Research And Information On Drugs) trend data have shown gradual decreases in prevalence rates of smoking, alcohol use, and many forms of illicit drug use among adolescents, there have been increases in some forms of substance use and abuse as well. Seventy three new psycho drastic substances have been detected in 2012 officially for the first time through the system of "Early Warning", 20 of which were synthetic Cannabinoid s [7]. According to the "European Monitor Center for Drug Abuse" [8], the most widespread synthetic stimulants in Europe are still amphetamines and ecstasy, substituting cocaine to some extent. It is estimated that about 12.7 million Europeans (aged 15-64) have used amphetamines at least once in their lives and about 2 million of them were used last year, while 11.4 million have used Ecstasy at least Once in their lives, about 2 million of them last year.

It has been estimated that 77 millions of European adults (15-64 years old) have used kanavis at least once in their life. It is worth noting the toxicity of herb cannabis, which in turn leads an increasing number of users to detox centers.

\section{Definition and Etiology}

Substance abuse can be defined as dangerous or maladaptive nonmedical use of a substance without implying dependence. In scientific terms substance dependence means that on drug cessation, an individual experiences pathological symptoms and signs. Research has shown that substance abuse results from different factors and conditions, such as social, personality, pharmacological, biological, and developmental factors [9] Social factors have been found as the most powerful influences promoting the initiation of abuse. These include the drug-related behavior and attitudes of significant others [10]. Poor family relationships and inadequate parenting practices (i.e., lack of parental monitoring) have been identified as risk factors for youth substance use as well [11]. Other social influences include popular media portrayals [12].

Additionally, substance use has been found to be associated with a number of individual characteristics such as high negative affect [13] low self-control [14], and high sensation-seeking tendency $[15,16]$. As a matter of fact, these characteristics are connected with psychological and biological mechanisms [17].

It must be underlined that individuals with specific psychiatric characteristics (e.g., anxiety, depression) might use particular substances as a way of alleviating these feelings, as the self-medication hypothesis suggests [18] Last but not least, recent animal research indicates that several drugs of abuse (cocaine, amphetamine, morphine, nicotine, and alcohol) with different molecular mechanisms of action affect the brain similarly by increasing strength at excitatory synapses on midbrain dopamine neurons $[19,20]$. It is a common neuro chemical pathway existing in different types of drug abuse. Furthermore, drug use progresses in a tragic sequence beginning in the early stages with cigarettes and alcohol, and progressing to the use of marijuana. The use of opiates, hallucinogens, and other illicit drugs mainly occurs later in the sequence of substance use addictions [21,22].

So, many prevention programs for adolescents target to delaying the onset of use among adolescents and young people, as this general pattern of drug use initiation and escalation has been documented by many researches all over the world [23]. As a result, many of these programs are provided to middle school or junior high school students because this is when many youth begin to try substances. These programs typically target the use of tobacco, alcohol, and marijuana, which is the most, used substances in western culture and is the first substances that adolescents typically experiment with and relevant Greek trends seem to follow the same pattern.

\section{Categorization of Prevention Approaches}

"Drug abuse prevention "is a commonly used term, but what does it really mean? And what does it mean to schools? "Drug prevention "or "drug abuse prevention"has three main components: "Demand reduction strategies", supply reduction strategies and Strategies to mitigate the negative health and social consequences of drug use. In this article we focus only on "Demand reduction strategies", which aim to reduce the desire and willingness to obtain and use drugs and to prevent, reduce or delay the uptake of drug use. They may include abstinenceoriented strategies [24].

In short, Prevention could be defined as follows: "A proactive process empowering individuals and systems to meet the challenges of life by creating and reinforcing conditions that promote healthy behaviors and prevent co-morbidity, relapse and disability" [25]. The United States Institute of Medicine classified Prevention programs as universal, selective, or indicated [26-27]. Universal programs target an entire population (e.g., a community or school) and focus on the general risk level concerning all group members. Although universal programs are designed using the general risk level assumption, typically no screening for substance abuse risk is performed before the program is implemented [27]. They assume that participants have never used substances and have the goal of preventing any future use despite the acknowledgment of variable risk-and variable current use-among participants.

Universal prevention programs are delivered to large groups without any prior screening for risk factors, so all members of the population share the same general risk, although the risk 
may vary greatly among individuals and sub-groups [8]. In school settings, universal prevention typically takes the form of alcohol awareness education, social and peer resistance skills, normative feedback, or development of behavioral norms and positive peer affiliations. Prevention programs can be either specific curricula delivered as school lessons, or classroom behaviour management programs, and can be educational, psychosocial, or a combination.

Psychosocial interventions aim to develop psychological and social skills (e.g. peer resistance) through modeling, understanding, norm-setting and social skill practice, so that young people are less likely to use substances. Educational interventions aim to raise awareness of the potential dangers of substance abuse [6]. Selective prevention programs serve individuals who exhibit high risk for future substance use based on personal- or environmental- level factors, such as being the child of an addict or living in a neighborhood where drugs are readily available. Like universal programs, the goal of selective programs is to prevent substance use initiation and onset. A third type, the indicated prevention program, targets youth who already use substances and attempts to reduce or discontinue substance use and prevent other risky behaviors [28].

\section{Greek Prevention Interventions}

The official Greek National Strategy on Drugs (2014-20) names drug prevention as one of its priorities. Drug prevention in Greece is mostly implemented by a nationwide network of 75 Prevention Centers for Addiction and Psychosocial Health Promotion, which were established within the framework of cooperation between the Organization against Drugs (OKANA) and local authorities and other stakeholders. Their activities include the prevention of all kinds of dependence and the promotion of psychosocial health. The Ministry of Education, other governmental and non-governmental drug services and health services are also active in the field of prevention [29].

OKANA'S action plan is structured into five pillars covering

a) Demand reduction (prevention; information and awareness rising; early detection and intervention; harm reduction; treatment; and social rehabilitation)

b) supply reduction

c) Coordination

d) Training, monitoring, research, evaluation; and

e) International cooperation.

As in other European countries, Greece evaluates its drug policy and strategy using ongoing indicator monitoring and specific research projects. The national focal point for the EMCDDA at the Mental Health Research Institute produces a range of epidemiological and other data annually that support this assessment work and provide insights into different aspects of drug problems in Greece.
In recent years, a number of selective prevention interventions targeting at-risk groups and individuals have been developed. According to the EKTEPN (2011) data concerning the universal Prevention interventions carried out in Greece in the context of Health Education during the School year 20072008 on the prevention of drug use and addressed Primary and Secondary School pupils showed that: A total of 701 teachers and 23,758 students participated in these programs of 683 Primary Schools, 745 teachers and 13. (540) students from 735 Secondary Schools.These numbers prove the very useful role of the prevention centers in Greece and underline the need for sound research into the inner workings and implementation of prevention programs [7].

The Icarus Prevention Unit (KETHEA) designs and implements interventions aimed at young offenders, young people who experiment with drugs, immigrants, returning migrants, refugees, disabled children, children from dysfunctional environments, at-risk families and children living in care institutions. In 2010, KETHEA opened a community intervention centre in Athens to work with young people from socially excluded families who exhibited delinquent behaviour and had drug use problems. Some Prevention Centers and agencies implement activities targeting young people who are experimenting with drugs or who have psychosocial problems, single-parent families, families from culturally diverse groups and immigrants. Indicated prevention activities are mainly individual or group counseling and referrals to other specialized services for students with psychological, emotional and social problems or special learning needs.

\section{Risk and protective factors}

According to the U.S. Department of Health and Human Services, research suggests that the risk for substance abuse increases as the number of risk factors increases, and that protective factor may reduce the risk of youth engaging in substance use that can lead to substance abuse. This interactive effect of risk and protective factors has serious implications for the design and implementation of successful preventive interventions. The more a program reduces risk factors and increases protective factors, the more it is likely to succeed in preventing substance abuse among children and youth [28-30].

So it is substantial to refer to some of the main risk factors for substance abuse, which are: Chaotic home environment, ineffective parenting, little mutual attachment and nurturing, inappropriate, shy, or aggressive classroom behavior, academic failure, low academic aspirations, poor social coping skills, affiliati0ns with deviant peers, perceived external approval of drug use (peer, family, community), parental substance abuse or mental illness [31]. Personality factors such as hopelessness, anxiety sensitivity, impulsivity, and sensation seeking have been shown to be concurrent or predictive risk factors for substance abuse in adolescence [32]. Anxiety sensitivity 
and hopelessness have been shown to be related to alcohol consumption as a response to managing anxiety31 or as means of stemming depressed feelings. Impulsive personality traits have been connected to antisocial characteristics in behavior during childhood and adolescence. Besides, excitement seeking is connected with substance abuse for enhancement causes $[33,34]$. Scientists have identified the following protective factors towards substance abuse: strong family bonds, parental engagement in child's life, clear parental expectations and consequences, academic success, strong bonds with pro social institutions (school, community, and church), conventional norms about drugs and alcohol [35-37].

\section{Kinds Of Effective Prevention Interventions}

There is a multitude of effective substance abuse prevention interventions, according to Substance Abuse and Mental Health Services Administration (SAMHSA) [38] that may have different areas of focus and can be implemented in a variety of settings. Interventions can involve the family, school, and community and may provide substance abuse prevention for an individual or a population of youth by focusing on environmental and community factors and policies, developmental factors, or skill development. The National Institute on Drug Abuse (NIDA) has identified key principles for prevention programs [39] based on risk and protective factors, the type of program, and the delivery of the program.

A variety of prevention approaches have been utilized especially in the US and Europe. The most effective researchbased approaches to the prevention of adolescent drug abuse stem from psychosocial theories and they deal mainly with the psychosocial risk and protective factors that promote the initiation and primary stages of drug use $[40,41]$. The social resistance skills approach to adolescent drug use prevention recognizes the role of various social factors that influence people. Among them, researches refer to the direct modeling of drug use behavior and social pressure from peers, persuasive advertising appeals and media portrayals that lead to alcohol, tobacco, and other drug use [42-46].

Therefore, social influence programs focus extensively on teaching youth how to recognize and resist pressures to use drugs and promote anti-drug use norms. The goal of these programs is to teach students to learn ways to avoid high-risk situations where they are likely to experience pressure to smoke, drink, or use drugs, as well as acquire the knowledge and skills needed to handle social pressure in these and other situations [44]. Another prevention approach combines social resistance skills training with competence enhancement skills building. According to the competence enhancement approach, drug use is conceptualized as a socially learned and functional behavior that is the result of interplay between social and personal factors. In addition to recognizing the importance of social learning processes such as modeling, imitation, and reinforcement, this approach suggests that youth with poor personal and social skills are not only more susceptible to influences that promote drug use, but also are motivated to use drugs as an alternative to more adaptive coping strategies [43].

Thus, competence enhancement approaches to adolescent drug abuse prevention refer to transmission of basic social and personal skills. Resistance skills are included as well. This kind of competence skills are decision-making skills, interpersonal communication skills, assertiveness skills, and skills for coping with anxiety and anger. Generally, more functional coping strategies contribute to better dealing with stressful life conditions [46-49]. Many meta-analytic studies emphasize that the social influence and competence enhancement approaches are more effective than traditional didactic approaches, and that attitude and behavior change are most substantial in high intensity, multi-component social resistance and/or competence enhancement programs implemented with booster sessions after the initial intervention [50].

Another universal prevention program among substance using youth is called keepin' it REAL [51], which is recognized as a model program by the Substance Abuse and Mental Health Services Administration (SAMHSA). The prevention program, named for the drug refusal skills it teaches (Refuse, Explain, Avoid, Leave), was developed as a culturally appropriate intervention, incorporating traditional ethnic values and practices that promote protection against drug use [52]. The program specifically identified aspects of Mexican American, European American and African American culture to develop a 10-lesson, classroom based curriculum that extended resistance and life skills models, using a culturally based narrative and performance framework. The objective was to enhance antidrug norms and attitudes and to facilitate the development of students' risk assessment, decision-making, and drug resistance skills. The randomized trial of keepin' it REAL documented the program's efficacy in preventing substance use, strengthening anti-drug attitudes, and drug resistance strategies [53]. last, but not least, effective treatment approach is The Life Skills Training (LST) program [54]. This primary prevention program for adolescent drug abuse shows the risk and a protective factor associated with substance use initiation and teaches skills leading to social resistance and enhancing social and personal competence. Life skills programs promote general competencies in interpersonal (e.g., assertiveness) and intrapersonal (e.g., self-esteem) domains. In addition, students acquire substancespecific skills and knowledge [55].

These programs help adolescents to master everyday challenges, as they try to complete their age-related developmental tasks, such as establishing new peer relationships. Another goal of life skills programs is to reduce the likelihood of substance use as a pseudo-mature behavior (e.g., imitating adult behavior by offering a cigarette to get closer to someone) or a coping strategy (e.g., as compensation for adolescent failure to complete developmental tasks [56] Findings from over two 
decades of evaluation research have indicated that this program corresponds to a variety of adolescent populations. These studies have demonstrated the positive behavioral effects of LST on the use of multiple substances and illicit drugs. It is worth noting that prevention effects last up until the end of adolescence.

Recapitalizing, school-based prevention programs against substance use were successful in the past if

a) They were delivered interactively, if

b) They taught skills to refuse drug offers and to resist pro-drug influences, if

c) They corrected misperceptions about usage normatively, and if

d) They enhanced social and personal competence [57]

All these characteristics seem to be adequately reflected in school-based prevention programs utilizing the aforementioned effective programs.

\section{Methodology}

Our research consisted of two phases that took part before and after an intervention. In the first phase, only professionals were interviewed targeting at their basic beliefs and difficulties concerning the implementation of intervention programs in the general population. Afterward, an intervention program, based on the main principles approved by the international scientific community, OKANA and the Greek ministry committee, was delivered to 30 schools selected for a pilot study. Finally, during the second phase of our research the aforementioned 30 professionals were interviewed to discuss their valuable experience and a sample of 100 students who participated in the program [8].

\section{Research Phase I}

The sample population in this phase selected by the research team was the scientists working at the Centers for the Prevention of the Dependence and Promotion of Psychosocial Health of OKANA and Local Government in the prefectures of Attica and Achaia.

\section{Inclusion And Exclusion Criteria}

The import criteria were defined as:

I. Respondents should belong to the scientific staff of the Prevention Centers and pupils should have personally taken part in a school based drug prevention program.

II. Their answers cover the full range of the interview

On the other hand, exclusion criteria were defined as:

I. Both categories of respondents (prevention officers and pupils) who do not belong to the sample population

II. Interviews which for whatever reason have been left unfinished
Quality method of interviewing was selected during this phase in order to examine in depth their beliefs, attitudes and beliefs concerning their previous experiences in prevention programs.

\section{Results (phase I)}

Sample's characteristics: The majority of respondents $(79.66 \%)$ they were women while the proportion of men was $20.34 \%$. The majority's (44.07\%) age was between 30 and 39 years. Respondents were mental health professionals, mainly psychologists and social workers well trained. The professional experience of $47.46 \%$ respondents working in the Prevention Centers was 12 years or older. During phase A the Interviewees were invited to present their opinions about their experiences in prevention programs, to describe in detail the pros and cons of those programs and to present their suggestions concerning the young adolescents who are at risk. Additionally, they were asked to describe the effects of the current fiscal crisis on their working conditions in the substance prevention centers and on the young people's mentality. Finally, the participants described the main problem areas they had faced in the past and suggested key proposals and solutions for the design of a new, more ambitious intervention.

As a matter of fact, $82 \%$ of participants had participated, in the past, in Interventions based on the didactic presentation of factual information concerning drugs. Their ambition, then, was to increase adolescents' knowledge and change consequently their attitudes. However, these prevention approaches have in some cases influenced knowledge and attitudes, but they have not been found to change behavior. The overwhelming majority (89.83\%) of respondents underlined that the economic crisis has adversely affected the operating conditions in the Centers for Prevention and thus decreased the prevention programs realized. Most of them were willing to participate in our research intervention and were convinced that school-based interventions should be a priority.

\section{Intervention}

Intervention's design and implementation were based on scientific researches and prevention approaches that were proved to "work". An interdisciplinary scientific committee selected data from a variety of school-based interventions and they adjusted some of them in the Greek mentality and ethnicity particularities and delivered it to Greek schools whose teachers were willing to cooperate with OKANA's pilot program. In our research, Universal prevention programs were implemented, given the fact that those programs' strategies address the entire population within a particular setting (schools, colleges, families, community). Universal prevention's ambition is to deter or to delay the onset of a disorder or problem by providing all individuals the information and skills necessary to prevent the problem. Universal prevention programs are delivered to large groups without any prior screening for risk factors, so all 
members of the population share the same general risk, although the risk may vary greatly among individuals and sub-groups.

As a matter of fact, 30 health professionals well trained realized this project. 100 students, aged 15-17 years old, declared that they were interested in participating in the intervention, of course with their parental license. Clinical setting of the intervention was a classroom in each school specially adjusted for the intervention that took place during an academic year.

Our intervention's model was a synthetic one using methods from the effective programs presented in this article's introduction. Life skills programs promote general competencies in interpersonal (e.g., assertiveness) and intrapersonal (e.g., self-esteem) domains. In addition, students acquire substance-specific skills and knowledge [56] these programs help adolescents to master everyday challenges, as they try to complete their developmental tasks, such as creating new peer relationships. Another target of life skills programs is to reduce the likelihood of substance use as a pseudo-mature behavior (e.g., imitating adult behavior by offering a cigarette to get closer to someone) or a coping strategy [57] (e.g., as compensation for adolescent failure to complete developmental tasks.

\section{Research Phase II}

After the intervention, interviews were addressed to the participants regarding their experiences. From the students, who participated, a sample from 100 students willing to collaborate with the research team was interviewed. The results were summarized as follows: The health scientists, basically psychologists and social workers described the difficulties that faced during this school-based intervention. Mainly, the overwhelming majority (83\%) described the positive emotional climate that was created, as it became clear to the students that the intervention would take place in small groups and it would be mainly interactive. However, they underlined the students' defense mechanisms and misperceptions regarding substance use. On the other hand, the majority of students (77\%) responded that they were glad to participate in that intervention. They appeared disappointed because of the present economical and moral crisis happening in Greece, but declared that they learned by experience to apply better coping mechanisms and they appreciated the life skills training methods, that they were taught. Some of them admitted that they had used alcohol and other substances as a means to face a variety of challenges and stressful factors, both personal and academic. Minorities of students (33\%) were very skeptical towards the intervention aforementioned and declared pessimistic towards any small intervention, if the main social problems, such as the unemployment, fiscal and moral values crisis, remained in the Greek society.

\section{Discussion}

Our research indicates the intervention's effect to professionals' beliefs and students' attitudes towards programs designed for substance abuse's prevention. The majority of professionals supported the aspect that the interventions' content affected the students positively and they interacted with interest. Their views comply with many researches about the effectiveness of similar program interventions, where participants responded positively to the seminars [58,59]. This study is the first of its kind to demonstrate that school-based targeted interventions are considered by professionals and by students to have positive results. As such, these kinds of interventions were found to be effective in preventing escalation in the frequency of drug use and preventing experimentation. It seems that similar approaches may be efficient to a subsample of high-risk youth as well. An important advantage of our synthetic approach presented in this article is that high-risk youth can be selected and targeted before they have initiated substance use, and they can be assisted in preventing onset to problematic use by managing early behavioral risk profiles.

The current results also provide, to our knowledge for the first time, promising evidence in favor of the efficacy of this intervention approach for preventing initiation of illicit drug use. Future efforts need to combine drug education with interventions targeting individual risk factors and should consider a more integrated approach in which drug education is also delivered in a personality-targeted way. Discussion Substance use and abuse is a widespread health, social and economic problem in Greece with the latest statistical data to document a rising number of teenage and adult addicts [7].

The Greek state in its concerted efforts to curtain and control the problem has established and operates an extensive network of drug prevention centers all over the country and in particular in Attica where most of the Greek citizens live. However, the lack of well-planned and large scale empirical research into the inner workings of prevention centers as well as the views of students involved in prevention programs has been a major hindrance so far. And this two phased research project is the first large scale attempt (for Greece's population and number of prevention centers included) to begin to understand institutional and working conditions in the daily routine of those centers. Few similar researches have been realized recently in Greece, but their target population was university students Previous small scale research project [60-63] delving into the operational conditions and prospects of Prevention Centers in Greece has come up with similar findings such as that the positive prospects for the development of Prevention Centers, as formulated by scientific staff of the centers, are subject to institutional change and rigid evaluation reviews. The shrinking of the work and the downgrading of their services seem to impose their institutional transformation for survival reasons.

As a result of our research project there appears a need for a clear and uniform operating framework by establishing internal regulations for the operation of the Prevention Centers, mainly on labor issues and redefining the function of the Prevention 
Centers and the context and structure of the Prevention programs implemented in schools. It is also necessary to improve the visibility of the Centers for Prevention, Networking and Interconnection with other local agencies. According to the results, the participants pay particular attention to primary universal prevention interventions, which they consider to focus on increasing protective factors and reducing risk factors, such as improving family communication and parenting. Particular importance is given by participants to school-related factors, psychological problems and peer groups, as well as wider social factors.

It is essential, for state policy makers, to decide an unequivocal future direction in the role and operation of prevention centers, focusing not only on tackling the understaffing and underfunding problems, as it has been indicated in other researches [64-65], but also on the wider issue of involving citizens, and institutions in the those centers' councils. Furthermore, prevention should become a way of life $\mathrm{n}$ community's and local communities' everyday life, rather than a posteriori intervention when substance use problems have already begun to appear.

Lastly, it is our view that state policy makers and those involved in planning, implementing and evaluating prevention programs should pay more attention to the need for more systematic research in the context of substance use prevention programs.

\section{Limitations}

This research refers to a pilot Greek study, and the participants were not from all over the country. External evaluators might focus on other aspects of this intervention. Furthermore, this trial did not include a placebo control condition, which would have strengthened the methodological value of the trial. Besides, all youth were exposed to some form of drug education and generic coping skills information, as well.

Future directions and clinical implications.

The next steps in further establishing the validity of this intervention approach will be the exploration of treatment utility and effectiveness. The majority (85\%) of adolescents identified as eligible for inclusion in this trial volunteered to participate in the intervention sessions, suggesting that the program could be easily adopted by schools if appropriate training and resources became available. It might be worthwhile to explore more sustainable strategies for implementing this school-based program. Besides, it will be important to examine the extent to which interventions targeting adolescents with personality risk factors could also lead to prevention of other mental health problems.

\section{Conclusion}

Our research underlines the necessity of school-based interventions and hopes to inspire future interventions to be implemented in all school settings all over the country. It verifies the main findings presented by the international scientific research, that is interactive interventions and prevention approaches based on decision-making sessions and life skills training methods may have positive effects on the majority of students who would participate. Follow- ups could stabilize the new habits and beliefs established by the intervention The main objectives of our large scale research were to record and analyze the views of both employees in prevention centers on the role of prevention centers in tackling substance dependence, the importance of their work within the community, the characteristics of a prevention intervention, the main risk factors for substance dependence.

Furthermore, it presented the difficulties which have arisen due to the recent financial crisis in Greece, the operation of these centers, as well as the proposals of the participants on improving working conditions and program delivery performance. In addition, the views of a large sample of school students have been elicited in a concerted attempt to better understand the pros and cons of the drug prevention programs implemented in Greek schools, as well as particular ways and elements which may add to those programs a lasting effect.

In particular, our research underlines the necessity of schoolbased interventions and hopes to inspire future interventions to be implemented in all school settings all over the country. It verifies the main findings presented by the international scientific research, that interactive interventions and prevention approaches based on decision-making sessions and life skills training methods may have positive effects on the majority of students who would participate. In today's world, where drug use is common, building adolescents' drug-resistance skills and self-efficacy, while enhancing decision-making capacity could help them resist addiction. Follow- ups could stabilize the new habits and beliefs established by the interventions.

\section{References}

1. Medina-Mora ME (2005) Prevention of substance abuse: a brief overview. World Psychiatry 4(1): 25-30.

2. Jonathan P Caulkins, R Liccardo Pacula, Susan Paddock (2017) School Based Drug Prevention. Pittisburgh, USA, pp. 204.

3. Whiteford H, Degenhardt L, Rehm J, Baxter A, Ferrari A, et al. (2013) Global burden of disease attributable to mental and substance use disorders: findings from the Global Burden of Disease Study 2010. The Lancet 382(9904): 1575-1586.

4. Caulkins J, Pacula R, Paddock S, Chiesa J (2004) What we can--and cannot--expect from school-based drug prevention. Drug and Alcohol Review 23(1): 79-87.

5. National Institute for Health and Clinical Excellence (2017) PHSE Evidence Review - Secondary Education and FE, UK.

6. Foxcroft D, Tsertsvadze A (2012) Universal school-based prevention programs for alcohol misuse in young people. Cochrane Database Syst Rev May 11(5): CD009113.

7. 2011 National Report (2010 Data) To The Emcdda by the Reitox National Focal Point. Athens, Greece. 
8. The state of the Drugs problem in Europe (2012) European Monitoring Centre for Drugs and Drug Addiction. Europe.

9. Luthar S, D'Avanzo K (1999) Contextual factors in substance use: A study of suburban and inner-city adolescents. Development and Psychopathology 11(4): 845-867.

10. Dishion T, Owen L (2002) A longitudinal analysis of friendships and substance use: Bidirectional influence from adolescence to adulthood. Developmental Psychology 38(4): 480-491.

11. Griffin K, Botvin G, Scheier L, Diaz T, Miller N (2000) Parenting practices as predictors of substance use, delinquency, and aggression among urban minority youth: Moderating effects of family structure and gender. Psychology of Addictive Behaviors 14(2): 174-184.

12. McCool J, Cameron L, Petrie K (2004) Stereotyping the smoker: adolescents' appraisals of smokers in film. Tobacco Control 13(3): 308-314.

13. Shoal G, Giancola P (2003) Negative affectivity and drug use in adolescent boys: Moderating and mediating mechanisms. Journal of Personality \& Social Psychology 84(1): 221-233.

14. Wills TA, Ainette MG, Stoolmiller M, Gibbons FX, Shinar O (2008) Good Self-Control as a Buffering Agent for Adolescent Substance Use: An Investigation in Early Adolescence with Time-Varying Covariates. Psychol Addict Behav 22(4): 459-471.

15. Comeau N, Stewart S, Loba P (2001) The relations of trait anxiety anxiety sensitivity, and sensation seeking to adolescents' motivations for alcohol, cigarette, and marijuana use. Addict Behav 26(6): 803-825.

16. Kopstein AN, Crum RM, Celentano DD, Martin SS (2017) Sensation seeking needs among $8^{\text {th }}$ and $11^{\text {th }}$ graders: characteristics associated with cigarette and marijuana use. Drug Alcohol Depend 62(3): 195203.

17. Barrett LF (2009) The Future of Psychology: Connecting Mind to Brain Perspectives on psychological science : a journal of the Association for Psychological Science 4(4): 326-339.

18. Conrod P, Castellanos-Ryan N, Strang J (2010) Brief, PersonalityTargeted Coping Skills Interventions and Survival as a Non-Drug User Over a 2-Year Period During Adolescence. Archives of General Psychiatry. 67(1): 85-93.

19. Kandel D (2002) Stages and pathways of drug involvement. Cambridge University Press, UK.

20. Kandel D (2002) Drug Policies: Improving the Quality of the Relevant Debate. Addiction 97(6): 655-657.

21. Griffin K, Botvin G (2010) Evidence-Based Interventions for Preventing Substance Use Disorders in Adolescents. Child and Adolescent Psychiatric Clinics of North America 19(3): 505-526.

22. Division on Addiction (2017) Drugs of Abuse and Addiction.

23. Hyman S (1994) Why Does the Brain Prefer Opium to Broccoli? Harvard Review of Psychiatry 2(1): 43-46.

24. School Based education for drug abuse prevention (2002) United Nations office on Drugs and Crime, USA.

25. Dawn Elise Snipes (2009) Substance Use Prevention.

26. National Survey of Substance Abuse Treatment Services (N-SSATS): 2013 Samhsa.gov. 2017, USA.

27. Prevention Tactics (2006) Community Prevention Institute, USA.

28. Griffin K, Botvin G (2010) Evidence-Based Interventions for Preventing Substance Use Disorders in Adolescents. Child and Adolescent Psychiatric Clinics of North America 19(3): 505-526.
29. Greece Country Drug Report (2017) European Monitoring Centre for Drugs and Drug Addiction, Greece.

30. U.S. Department of Health and Human Services (2010) NIDA Preventing Drug Use among Children and Adolescents: A Research-Based Guide for Parents, Educators, and Community Leaders, $\left(2^{\text {nd }}\right.$ edn), A Research -Based Guide, USA.

31. Scheier L (2001) Etiologic Studies of Adolescent Drug Use:A Compendium of Data Resources and Their Implications for Prevention. The Journal of Primary Prevention 22(2): 125-168.

32. Mitchell MR, Potenza MN (2014) Addictions and Personality Traits: Impulsivity and Related Constructs. Current behavioral neuroscience reports 1(1): 1-12.

33. Conrod P, Castellanos-Ryan N, Strang J (2010) Brief, PersonalityTargeted Coping Skills Interventions and Survival as a Non-Drug User Over a 2-Year Period During Adolescence. Archives of General Psychiatry 67(1): 85-93.

34. Sinha R (2009) Stress and Addiction: A Dynamic Interplay of Genes, Environment, and Drug Intake. Biological Psychiatry 66(2): 100-101.

35. Sinha R (2008) Chronic Stress, Drug Use, and Vulnerability to Addiction. Annals of the New York Academy of Sciences 1141(1): 105-130.

36. Parsai M, Voisine S, Marsiglia FF, Kulis S, Nieri T (2009) The protective and risk effects of parents and peers on substance use, attitudes and behaviors of Mexican and Mexican American female and male adolescents. Youth \& society 40(3): 353-376.

37. Risk \& Protective Factors (2016) Behavioral Health Barometer, USA.

38. NREPP Find an Intervention. Substance Abuse and Mental Health Services Administration, USA.

39. Preventing Drug Use among Children and Adolescents (In Brief) NIH National Institute on Drug Abuse, USA.

40. Hawkins J, Catalano R, Miller J (1992) Risk and protective factors for alcohol and other drug problems in adolescence and early adulthood: Implications for substance abuse prevention. Psychological Bulletin 112(1): 64-105.

41. Center for Substance Abuse Treatment. Substance Abuse Treatment and Family Therapy (2004) Rockville (MD): Substance Abuse and Mental Health Services Administration, USA.

42. Botvin G (2000) Preventing drug abuse in schools. Addictive Behaviors 25(6): 887-897.

43. Barrett, P, Ollendick T (2017) Handbook of Interventions that Work with Children and Adolescents: Prevention and Treatment. Chichester West Sussex, Wiley\& Sons, England, UK.

44. Barkin S, Smith K, DuRant R (2002) Social skills and attitudes associated with substance use behaviors among young adolescents. Journal of Adolescent Health 30(6): 448-454.

45. Tawana Bandy BS, Kristin A Moore (2011) What Works For Promoting And Enhancing Positive Social Skills: Lessons From Experimental Evaluations Of Programs And Interventions. Washington DC, USA.

46. Hersen M, Rosqvist J, Gross A, Drabman R, Sugai G, et al. (2005) Encyclopedia of behavior modification and cognitive behavior therapy. Thousand Oaks Calif, Sage Publications, USA.

47. Theodoratou M, Tafiadis D, Fotiadou S (2006) Coping strategies by the Greek university students facing stress. Annals of General Psychiatry 5(Suppl 1): S221.

48. Theodoratou M, Tafiadis D, Mpekos V, Euaggelatou M, Kiritsi B, et al. (2006) Coping Strategies of Greek Students Annals of General Psychiatry 5(Suppl 1): S222. 
49. Theodoratou-Bekou M (2008) Psychological maturing and coping strategies. Group work 18(1): 76-98.

50. Theodoratou M, M Nikolopoulou, E Bekos, O Papadopoulos (2011) 2017 How students cope with academic stress and stressful life events. Greece.

51. Tobler N, Stratton H Tobler NS (1997) Effectiveness of School-based drug prevention programs: A meta-analysis of the research. The Journal of Primary Prevention 18(1): 71-128.

52. kiR - keepin' it REAL (1989) An Effective, Multicultural Middle School Drug Prevention Program Penn State University, USA.

53. Castro F, Alarcón E (2002) Integrating Cultural Variables into Drug Abuse Prevention and Treatment with Racial/Ethnic Minorities. Journal of Drug Issues 32(3): 783-810.

54. Hecht M, Marsiglia F, Elek E, Wagstaff D, Kulis S, et al. (2003) Culturally Grounded Substance Use Prevention: An Evaluation of the keepin' it R.E.A.L. Curriculum. Prevention Science 4(4): 233-248.

55. Botvin G, Baker E, Dusenbary L, Stephanie Tortu, Elizabeth M Botvin (1990) "Preventing Adolescent Drug Abuse Through a Multimoda Cognitive-Behavioral Approach: Results of a 3-Year Study." Journal of Consulting and Clinical Psychology 58(4): 437-446.

56. Botvin G, Griffin KW, Tracy Diaz, Lawrence M Scheier, Christopher Williams, et al. (2000) "Preventing illicit drug use in adolescents: Long-term follow-up data from a randomized control trial of a school population." Addictive Behaviors 25(5): 769-774.

57. Botvin G, Griffin K (2014) Life skills training: Preventing substance misuse by enhancing individual and social competence. New Directions for Youth Development 141: 57-65.

58. Griffin KW, Botvin GJ (2010) Evidence-Based Interventions for Preventing Substance Use Disorders in Adolescents. Child and adolescent psychiatric clinics of North America 19(3): 505-526.

59. School Based Education for drug abuse prevention (2004), Newyork, USA.

60. Griffin K, Botvin G, Nichols T, Doyle M (2003) Effectiveness of a Universal Drug Abuse Prevention Approach for Youth at High Risk for Substance Use Initiation. Preventive Medicine 36(1): 1-7.

61. Prevention and Evaluation Resources Kit (2010) European Monitoring Centre for Drugs and Drug Addiction, Europe.

62. Loizou D, Stogiannidou A (2016) Substance abuse prevention among Greek emerging adults: Evaluation of a psycho-educational counselling intervention. The European Journal of Counselling Psychology 5(1): $18-42$.

63. Kounenou K (2011) Drug use by Greek university students and preventive actions. Procedia - Social and Behavioral Sciences 15: 456460 .

64. Triantafilloy P (2006) The development of substance abuse prevention centers in the local societies. Panteion University of Athens, Greece.

65. Dritsas I, Theodoratou M, Margaris T, Christodoulidis S, Valsami O (2016) An empirical study of the working conditions in the drug prevention centers of Attika, Greece: New prospects and possibilities in an era of uncertainty. European Psychiatry 33: S479.

\section{Your next submission with Juniper Publishers will reach you the below assets}

- Quality Editorial service

- Swift Peer Review

- Reprints availability

- E-prints Service

- Manuscript Podcast for convenient understanding

- Global attainment for your research

- Manuscript accessibility in different formats

( Pdf, E-pub, Full Text, Audio)

- Unceasing customer service

Track the below URL for one-step submission https://juniperpublishers.com/online-submission.php 